\title{
Correction to: Projected Metabolic Consequences of Post-Traumatic Osteoarthritis and the Aging Population
}

Rian Q. Landers-Ramos ${ }^{1}$ (D) - Lisa E. Custer ${ }^{1}$

Published online: 18 February 2021

(C) Springer Science+Business Media, LLC, part of Springer Nature 2021

\section{Correction to: Current Geriatrics Reports https://doi.org/10.1007/s13670-020-00350-6}

The original version of this article unfortunately contained some mistakes.

There is an error in how some of the values in our recent publication "Projected Metabolic Consequences of Posttraumatic Osteoarthritis and the Aging Population".

In the paragraph - Effects of Aging on Metabolic Cost of Movement, there is a line stating. Results from the Baltimore Longitudinal Study on Aging found that having an energetic cost of walking of $>0.17 \mathrm{~mL} / \mathrm{kg} / \mathrm{min}$ resulted in a $57 \%$ higher risk of developing slow gait speed $(<1.0 \mathrm{~m} / \mathrm{s})$ compared with individuals with energetic cost of walking $<0.17 \mathrm{ml} / \mathrm{kg} / \mathrm{min}$. A recent meta-analysis reported that older adults expended approximately $0.38 \mathrm{~J} / \mathrm{kg} / \mathrm{min}$ more energy than younger adults at the same walking speed". In the same paragraph there is a line stating "However, they did note differences between the youngest, 18-40-year old, group $(2.17 \pm 0.33 \mathrm{~J} / \mathrm{kg} / \mathrm{min})$ and the oldest group $\geq 70$ years old $(2.37 \pm 0.33 \mathrm{~J} / \mathrm{kg} / \mathrm{min}) "$.

In these lines, the unit of metabolic cost is mistakenly reported as $\mathrm{J} / \mathrm{kg} / \mathrm{min}$, instead of $\mathrm{J} / \mathrm{kg} / \mathrm{m}$, where $\mathrm{m}$ stands for meters.

The original paper has been corrected.

Publisher's Note Springer Nature remains neutral with regard to jurisdictional claims in published maps and institutional affiliations.

The online version of the original article can be found at https://doi.org/ $10.1007 /$ s $13670-020-00350-6$

Rian Q. Landers-Ramos

rlandersramos@towson.edu

Lisa E. Custer

1custer@towson.edu

1 Department of Kinesiology, Towson University, 8000 York Rd, Towson, MD 21252, USA 